\title{
ANALISIS BIAYA OPERASI KENDARAAN DI WILAYAH TANGERANG DENGAN METODE PACIFIC CONSULTANT INTERNATIONAL
}

\author{
Sri Nuryati, Saiful Haq \\ Program Studi Teknik Sipil, Fakultas Teknik \\ Universitas Muhammadiyah Tangerang \\ E-mail: nur_unis@yahoo.com
}

\begin{abstract}
ABSTRAK
Kota Tangerang merupakan salah satu wilayah perkotaan di Jabodetabek yang padat lalu lintasnya dimana jumlah kendaraan terus mengalami peningkatan setiap tahunnya, hal ini akan menyebabkan terjadinya penurunan tingkat pelayanan jalan yang disebabkan oleh kemacetan lalu lintas terutama pada jamjam sibuk. Penurunan tingkat pelayanan jalan berpengaruh terhadap besarnya biaya operasional kendaraan (BOK), terutama dalam hal pemborosan bahan bakar dan waktu perjalanan menjadi lebih lama. Pengembangan beberapa metode telah dilakukan untuk menghitung besarnya BOK, analisis model HDM-4 RUE mempunyai parameter yang lebih banyak di bandingkan metode lainnya, tetapi kecepatan kendaraan lebih signifikan dalam perhitumgan BOK.

Pada penelitian ini analisis BOK dihitung menggunakan metode PCI ((Pacific Consultant International, Inc). Hasil analisis BOK di wilayah Kota Tangerang pada kecepatan rata-rata kendaraan $25 \mathrm{~km} / \mathrm{jam}$ untuk jenis kendaraan mobil penumpang (Car) sebesar Rp. 1.973.585,-/1000km, kendaraan Utility sebesar Rp. 1.359.127,-/1000km, Smaal Bus sebesar Rp. 4.07.054, Large Bus sebesar Rp. 5.076.54,-/1000km, Light Truck sebesar Rp. 3.815.392,-/1000km dan Heavy Truck adalah sebesar Rp. 6.464.542,-/1000 km.
\end{abstract}

Kata Kunci: Biaya Operasional Kendaraan (BOK).

\section{PENDAHULUAN}

Wilayah Tangerang termasuk wilayah yang padat lalu lintasnya terutama pada jam-jam sibuk pagi dan sore hari. Kendaraan pribadi memberikan konstribusi besar terhadap penurunan tingkat pelayanan jalan dibandingkan dengan kendaraan umum. Rendahnya tingkat pelayanan jalan (Level of Service, LOS) berdampak terhadap besarnya biaya bagi pengguna jalan (Road User Cost, RUC) terutama dalam hal pemborosan bahan bakar dan waktu terbuang sia-sia (Tamin O.Z., 2000). Semakin tinggi kecepatan kendaraan pada suatu ruas jalan maka biaya yang ditimbulkannya akan semakin rendah demikian juga sebaliknya (Bennett, R., 2003). Hasil survei kecepatan kendaraan rata-rata di wilayah Jabodetabek adalah berkisar antara 10-70 km/jam (Data survei IRMS 2012).

Berdasarkan hal tersebut diatas maka perlu dilakukan perhitungan terhadap biaya operasi kendaraan (BOK) di wilayah
Tangerang dengan menggunakan beberapa metode yang telah dikembangkan.

\section{ROAD USER COST (RUC)}

Biaya pengguna jalan (road user cost, RUC) adalah biaya yang dikeluarkan oleh pemakai jalan dalam bertransportasi baik berkendaraan umum maupun kendaraan pribadi. Komponen utama RUC adalah biaya operasi kendaraan (Vehicle operating cost, VOC) dan nilai waktu (Value of Time, VOT) (Bennett R., 2003 dan Bertha M., 2011). Komponen-komponen yang mempengaruhi besarnya RUC adalah kecepatan kendaraan, kondisi jalan (road condition), kekasaran permukaan jalan (Roughness), jenis kendaraan, geometrik jalan, lengkung jalan (curvature), lingkungan, iklim, dan gaya pengemudi (Bennett R., 2003). Nilai waktu (Value of Time, VOT) untuk masingmasing wilayah adalah berbeda-beda, tergantung dari tingkat pendapatan seseorang, semakin besar pendapatan seseorang maka nilai waktu yang di timbul- 
kannya akan semakin besar, demikian juga sebaliknya.

Beberapa metode telah di kembangkan untuk menganalisis besarnya biaya pengguna jalan (Road User Cost, RUC), yaitu antara lain model HDM-4 RUE (Highway Development and Management Road User Cost Effect) yang di prakarsai oleh Bank Dunia (Work Bank) yang telah dikembangkan di Portugis dengan model Portuguese Roud User Cost Model (VOC PTRUC), di Selandia baru dengan New Zealand Vehicle Operating Cost Model (NZVOC), di Inggris bagian Utara dan Irlandia Utara dengan Cost Benefit Analysis Model (COBA). Sedangkan di Indonesi analisis BOK di kembangkan oleh Bina Marga dengan model Indonesian Highway Capacity Manual (IHCM, 1995) dan model PCI (Pacific Consultans International Inc. Tokyo Jepang) yang bekerja sama dengan Lembaga Afiliansi Penentilitian dan Industri Institut Teknologi Bandung (LAPI ITB, 1996) dan PT Jasa Marga Indonesia untuk jalan tol dan jalan non tol. Model HDM-4 mempunyai parameter lebih banyak di bandingkan dengan model lainnya, tetapi dari masing-masing model tersebut kecepatan kendaraan yang lebih signifikan dalam menghitung BOK.

\section{BIAYA OPERASI KENDARAAN (BOK)}

Biaya Operasional Kendaraan (BOK) adalah biaya ekonomis yang terjadi dengan dioperasikannya suatu kendaraan pada kondisi normal untuk suatu tujuan tertentu. Pengertian biaya ekonomi yang dimaksud disini adalah biaya yang sebenarnya terjadi (Hudoyo R., 2006). Biaya operasional kendaraan di pengaruhi oleh kecepatan kendaraan, jenis kendaraan, geomtrik jalan, kekasaran permukaan jalan, dan gaya pengemudi.

Menurut Bina Marga, 1995 dan Sistem Perencanaan Angkutan Umum ITB, 1997, biaya operasi kendaraan (BOK) terdiri dari:

1. Biaya tetap (Standing cost atau fixed cost) adalah biaya tetap yang harus dikeluarkan secara rutin untuk jangka waktu tertentu dan tidak terpengaruh oleh operasional kendaraan tersebut, yaitu meliputi :
a. Biaya depresiasi
b. Biaya bunga modal (interest cost)
c. Biaya asuransi
d. Biaya overhead

2. Biaya tidak tetap (variable cost or running cost)

adalah biaya yang harus dikeluarkan sesuai dengan jarak tempuh dan tergantung pada pemakaian kendaraan sehingga dapat dirasakan secara langsung, yaitu terdiri dari:
a. Biaya konsumsi bahan bakar
b. Biaya konsumsi oil
c. Biaya konsumsi ban
d. Biaya pemeliharaan
e. Biaya awak kendaraan

\section{ANALISI BOK METODE PCI}

Pada penelitian ini analisis BOK menggunakan metode perhitungan model PCI (Pacific Consultants International) untuk jalan non-tol, yaitu merupakan penjumlahan dari biaya tidak tetap (variable cost) dan biaya tetap (Standing Cost), yang dipengaruhi oleh kecepatan kendaraan dan jenis kendaraan yang di gunakan. Persamaan-persamaan model PCI adalah sebagai berikut:

\section{Konsumsi Bahan Bakar Minyak}

Persamaan konsumsi bahan bakar metode PCI adalah sebagai berikut:

Sedan (PC) : Y = 0,03719S*S-4,19966S + 175,9911 Bus Kecil/Sedang : $Y=0,06846 \mathrm{~S} * \mathrm{~S}-8,02987 \mathrm{~S}+$ 340,6040

Bus Besar $\quad: Y=0,12922 S * S-13,68742 S+541,0279$

Truk Kecil $\quad: Y=0,06427 S^{*} S-7,06130 S+318,3326$

Truk Besar $\quad: Y=0,11462 S * S-12,85594 S+503,71$

Dimana:

$\mathrm{Y}=$ Konsumsi bahan bakar (Itr/1000 km)

$\mathrm{S}=$ Running Speed $(\mathrm{Km} / \mathrm{Jam})$

\section{Konsumsi Oil:}

Persamaan konsumsi oil metode PCI adalah sebagai berikut:

Sedan (PC) : $Y=0,00025 S * S-0,02664 S+1,441710$ Bus Kecil/Sedang : $\mathrm{Y}=0,00057 \mathrm{~S} * \mathrm{~S}-0,06130 \mathrm{~S}+$ 3,317530

Bus Besar $\quad: Y=0,00030 S * S-0,12968 S+7,062390$

Truk Kecil $: Y=0,00048 S * S-0,05608 S+3,073830$

Truk Besar $\quad: Y=0.00100 S * S-0.11715 S+6.409620$

\section{Konsumsi Ban}

Perbandingan konsumsi ban di jalan tol dan jalan arteri

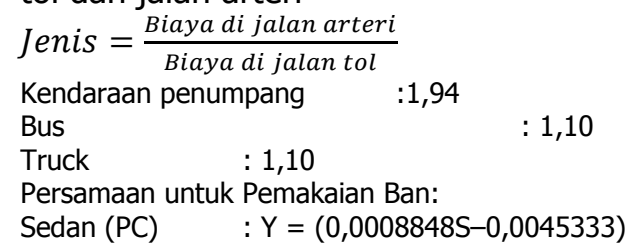


Bus Kecil/Sedang : $Y=(0,0012356 S-0,0064667)$

Bus Besar $\quad: Y=(0,0012356 S-0,0064667)$

Truk Kecil $\quad: Y=(0,0011553 S-0,0005933)$

Truk Besar $\quad: Y=(0,0011553 S-0,0005933)$

Dimana:

$\mathrm{Y}^{\prime}=\mathrm{Y}^{*} \mathrm{jml}$ ban*harga ban $/ 1000 \mathrm{~km}$

\section{Biaya Pemeliharaan dan Perbaikan}

Biaya pemeliharaan terdiri dari biaya untuk pembelian onderdil (spare part) dan upah tenaga kerja:

\section{a. Biaya suku cadang}

Perbandingan antara konsumsi suku cadang di jalan tol dan jalan arteri:

$$
\text { Jenis }=\frac{\text { Biaya di jalan arteri }}{\text { Biaya di jalan tol }}
$$

Kendaraan penumpang : 1,73

Bus : : 1,27

Truck : 1,26

Persamaan Suku cadang:

Sedan (PC) : $Y=(0,0000064 S+0,0005567)$

Bus Kecil/Sedang $: Y=(0,0000320 S+0,0020891)$

Bus Besar : $Y=(0,0000320 S+0,0020891)$

Truk Kecil : $Y=(0,0000191 S+0,0015400)$

Truk Besar : $Y=(0,0000191 S+0,0015400)$

Dimana:

$\mathrm{Y}^{\prime}=\mathrm{Y}^{*}$ nilai kendaraan $(/ 1000 \mathrm{~km})$

$\mathrm{S}=$ Running Speed $(\mathrm{Km} / \mathrm{Jam})$

\section{b. Biaya Pemeliharaan}

Persamaan biaya tenaga kerja pemeliharaan metode PCI adalah sebagai berikut:

Sedan (PC) : $Y=(0,00362 S+0,36267)$

Bus Kecil/Sedang : $Y=(0,02311 S+1,97733)$

Bus Besar : $Y=(0,02311 S+1,97733)$

Truk Kecil : $Y=(0,01511 S+1,21200)$

Truk Besar : $Y=(0,01511 S+1,21200)$

Dimana:

$\mathrm{Y}^{\prime}=\mathrm{Y}^{*}$ ongkos mekanik perjam (/1000 km)

\section{Deprisiasi (penyusutan)}

Persamaan biaya penyusutan kendaraan metode PCI adalah sebagai berikut:

$\begin{array}{lll}\text { Sedan }(\mathrm{PC}) & : & \mathrm{Y}=\frac{1}{2,5 \mathrm{~S}+125} \\ \text { Bus } & : & \mathrm{Y}=\frac{1}{8,756 \mathrm{~S}+350} \\ \text { Truk } & : & \mathrm{Y}=\frac{1}{6,129 \mathrm{~S}+245}\end{array}$

Dimana:

$\mathrm{Y}=$ Penyusutan kendaraan per $1000 \mathrm{~km}$, dikalikan dengan harga kendaraan

$\mathrm{S}=$ Running Speed $(\mathrm{Km} / \mathrm{Jam})$

\section{Biaya Suku Bunga Modal}

Persamaan untuk suku bunga modal (Interest Cost) model PCI adalah sebagai berikut:
Sedan (PC)

$$
\mathrm{Y}=\frac{120}{500 \mathrm{~S}}
$$

Bus

Truk

Dimana:

$\mathrm{Y}=$ Suku bunga per $1000 \mathrm{~km}$, dikalikan dengan 1/2 dari nilai kendaraan.

Suku bunga $=12 \%$ per tahun

$\mathrm{S}=$ Running Speed $(\mathrm{Km} / \mathrm{Jam})$

\section{Biaya Asuransi}

Persamaan biaya asuransi metode PCI adalah sebagai berikut:

$\begin{array}{lll}\text { Sedan (PC) } & : & \mathrm{Y}=\frac{35,0 \times 0,5}{500 \mathrm{~S}} \\ \text { Bus } & : & \mathrm{Y}=\frac{40,0 \mathrm{0} 0,5}{2500 \mathrm{~S}} \\ \text { Truk } & : & \mathrm{Y}=\frac{60,0 \times 0,5}{1750 \mathrm{~S}}\end{array}$

Dimana:

$\mathrm{Y}=$ Biaya asuransi per $1000 \mathrm{~km}$, dikalikan dengan nilai kendaraan

$\mathrm{S}=$ Running Speed $(\mathrm{Km} / \mathrm{Jam})$

\section{Biaya Awak Kendaraan}

Persamaan biaya awak kendaraan metode PCI adalah sebagai berikut:

$\begin{array}{lll}\text { Bus } & : & \mathrm{Y}=\frac{1000}{\mathrm{~S}} \\ \text { Truk } & : & \mathrm{Y}=\frac{1000}{\mathrm{~S}}\end{array}$

Dimana:

$\mathrm{Y}=$ Waktu perjalanan per $1000 \mathrm{~km}$ (dikalikan dengan faktor pengali crew kendaraan)

$\mathrm{S}=$ Running Speed $(\mathrm{Km} / \mathrm{Jam})$

Tabel 1.1.: Rata-rata faktor pengali untuk awak kendaraan per kendaraan:

\begin{tabular}{|c|c|c|}
\hline \multirow{2}{*}{ Jenis Kendaraan } & \multicolumn{2}{|c|}{ Faktor Pengali Crew per Kendaraan } \\
\cline { 2 - 3 } & Supir & Kondektur \\
\hline Bus Kecil & 1 & 1,7 \\
Bus Besar & 1 & 2 \\
Truk Kecil & 1 & 1 \\
\hline Truk Besar & 1 & 2 \\
\hline
\end{tabular}

Sumber: metode PCI

\section{Biaya Overhead (Overhead Cost)}

Biaya overhead menurut metode PCI dihitung sebesar $10 \%$ dari jumlah biaya langsung dan biaya tidak langsung atau dapat ditulis:

Bus : $10 \%$ dari sub total biaya operasi kendaraan di atas

Truk: $10 \%$ dari sub total biaya operasi kendaraan di atas. 
NILAI WAKTU (Value of Time, VOT)

Nilai waktu adalah sejumlah uang yang disediakan seseorang untuk dikeluarkan (atau dihemat) untuk menghemat satu unit waktu perjalanan. Nilai Waktu bertambah secara proporsional dengan pendapatan seseorang, semakin besar tingkat pendapatan per kapitanya maka semakin besar pula nilai waktunya (Eko D., 2002). Nilai Waktu (Value of Time, VOT) untuk masing-masing wilayah adalah berbeda-beda tergantung dari tingkat pendapatan perkapita seseorang, moda transportasi yang digunakan, kecepatan kendaraan dan tujuan perjalanan (Bertha M., 2011 dan Eko D., 2002).

\section{METODOLOGI PENELITIAN}

Metode penelitian merupakan kerangka penulisan penelitian dan pengumpulan data-data yang digunakan dalam analisis penelitian, biasanya di gambarkan dalam bentuk flow chart atau alur penelitian.

\section{Data Sekunder}

Data sekunder di sebut juga data yang tersedia yaitu merupakan data yang diperoleh atau dikumpulkan dari sumber-sumber yang telah ada. Data sekunder pada penelitian ini berupa data:

1. Kecepatan kendaraan $(\mathrm{km} / \mathrm{jam})$

2. Pendapatan rata-rata per bulan untuk kendaraan pribadi

\section{Data Primer}

Data primer atau disebut juga data asli yaitu data yang diperoleh atau dikumpulkan oleh orang yang melakukan penelitian dengan cara pengamatan melalui survei langsung atau browsing melalui internet. Data primer pada penelitian ini berupa:

1. Kendaraan representatif

2. Komponen BOK

\section{Unit Biaya dan Kendaraan Representatif}

Kendaraan reprensentatif adalah kendaraan yang mewakili dari beberapa jenis kendaraan yang hampir sama karakteristiknya dan dikelompokkan menjadi beberapa kelompok atau golongan yaitu dikelompokkan berdasarkan berat kosong kendaraan ditambah dengan berat muatan atau GVW (Gross Vehicle Weight).
Tabel 1.2.: Kendaraan representatif GVW

\begin{tabular}{|l|l|}
\hline Type Vehicle & GVW $(\mathrm{kg})$ \\
\hline Car & $800-2.000$ \\
\hline Utility & $1.100-2.500$ \\
\hline Small Bus & $7.500-12.000$ \\
\hline Large Bus & $7.500-12.000$ \\
\hline Light Truck & $3.000-6.500$ \\
\hline Heavy Truck & $6.000-32.000$ \\
\hline
\end{tabular}

Sumber: VOCM-HDM-III, LAPI ITB

Bandung, 1996

\section{Unit Biaya}

Unit biaya adalah unit-unit biaya yang berhubungan dengan data yang di gunakan dalam analisis penelitian berupa harga-harga. Unit biaya dan jenis Kendaraan yang digunakan pada penelitian ini seperti terdapat pada tabel 1.3 . berikut:

Tabel 1.3. Unit Biaya Komponen BOK dan

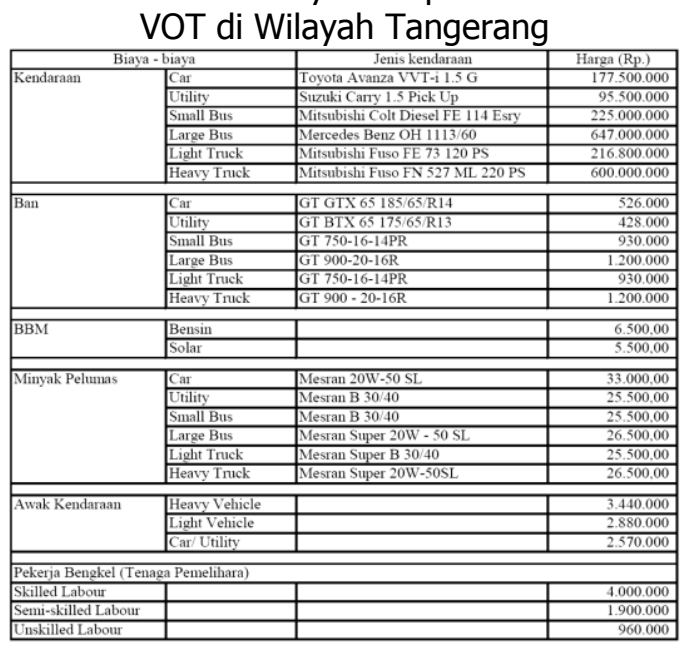

Sumber: http//blogspot.com , hasil survei dan wawancara

\section{Biaya Awak Kendaraan}

Biaya awak adalah biaya yang dikeluarkan perusahaan kendaraan oleh pemilik kendaraan bermotor (jenis komersial), untuk membayar upah operator (penge-mudi dan pembantu/kernet). Data yang digunakan berasal dari hasil wawancara dengan para awak kendaraan. Hasil wawancara gaji awak kendaraan seperti pada tabel berikut: 
Tabel 1.4. Perhitungan gaji awak kendaraan wilayah Jabodetabek tahun 2013

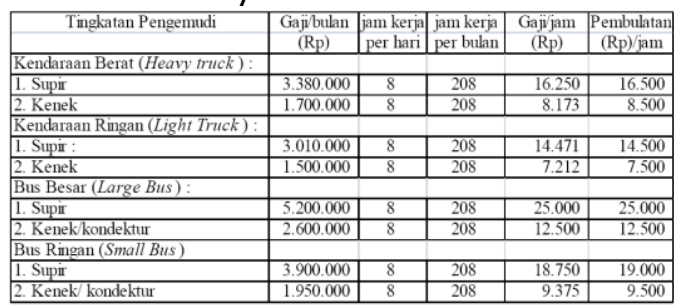

Sumber: Hasil analisis dan hasil wawancara

\section{UJI KENORMALAN DATA}

Pengujian kenormalan data pada penelitian ini bertujuan untuk mengetahui apakah data yang digunakan berdistribusi normal atau tidak yaitu dengan uji statistik cara Lilliefors, yaitu berupa data kecepatan kendaraan di wilayah Tangerang. Berdasarkan hasil pengujian cara lilliefors data yang digunakan adalah berdistribusi normal atau data dapat diterima, dimana Lhitung (Lo) < Ltabel, atau Ho dapat diterima. Data kecepatan kendaraan seperti pada tabel 1.5 dan hasil pengujian kenormalan data seperti pada tabel 1.5 berikut ini:

Tabel 1.5. : Data Kecepatan Kendaraan Di Wilayah Tangerang

\begin{tabular}{|c|c|c|c|}
\hline Nilai interval & Nilai Tengah & Frekuensi & Frekuensi (f relatif) $\%$ \\
\hline $10-18$ & 14 & 54 & 67,50 \\
\hline $19-27$ & 23 & 0 & 0,00 \\
\hline $28-36$ & 32 & 1 & 1,25 \\
\hline $37-45$ & 41 & 4 & 5,00 \\
\hline $46-54$ & 50 & 10 & 12,50 \\
\hline $55-65$ & 59 & 10 & 12,50 \\
\hline $64-74$ & 69 & 1 & 1,25 \\
\hline \multicolumn{5}{|l|}{ Jumlah } & 80 & 100,00 \\
\hline
\end{tabular}

\section{HASIL ANALISIS BOK}

Pada penelitian ini analisis Biaya Operasi Kendaraan di wilayah Tangerang di hitung dengan menggunakan metode PCI (Pacific Consultan Internationa). Hasil analisis biaya operasi kendaraan di wilayah Tangerang dengan kecepatan rata-rata 25 $\mathrm{km} /$ jam (Data IRMS, 2013) seperti terdapat pada tabel berikut:

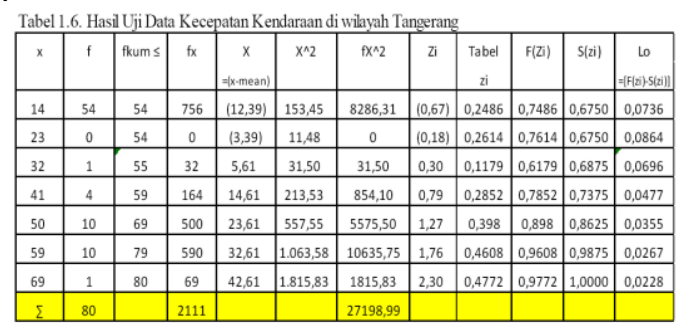

Sumber: Hasil perhitungan BOK model PCI

\section{KESIMPULAN}

1. Biaya operasi kendaraan di pengaruhi oleh kecepatan kendaraan, semakin tinggi kecepatan kendaraan maka biaya yang di timbulkan akan semakin rendah dan semakin rendah kecepatannya maka biaya yang di timbulkannya akan semakin besar.

2. Biaya operasi kendaraan pada masingmasing wilayah adalah berbeda-beda tergantung dari tingkat pelayanan jalan raya dan Nilai waktu perjalanan.

3. Hasil analisis BOK di wilayah Tangerang pada kecepatan rata-rata $25 \mathrm{~km} / \mathrm{jam}$ pada jenis kendaraan Heavy Truck yaitu sebesar Rp. 6.464.542,- /1000 km, Large bus sebesar Rp. 5.431.784,$/ 1000 \mathrm{~km}$, Small bus sebesar Rp. 4.076.054,- /1000 km, Light Truck sebesar Rp. 3.815.392,-/1000 km, Car sebesar Rp. 1.973.585,- /1000km dan Utility sebesar Rp. 1.359.127,- /1000 $\mathrm{km}$.

\section{SARAN}

1. Penelitian ini diharapkan dapat digunakan sebagai bahan masukan untuk penelitian berikutnya.

2. Perlu dilakukan pegembangan penggunaan beberapa metode perhitungan BOK untuk mendapatkan hasil yang lebih baik dari metode sebelumnya.

\section{DAFTAR PUSTAKA}

Bennett R. Christopher, 2003, Modelling Road User and Environmental Effect in HDM-4 RUE. Volume 7, The University of Birmingham Edgbaston, United Kingdom.

Bertha Maria dos Santos, 2011, Journal Vehicle Operating, Accident and User Time Costs in Pavement Management Systems: Approach for Portuguese Conditions, Volume 5, No. 8 (Serial No. 45), pp. 723-731

Bina Marga Dep. PU, 1995, Perhitungan Biaya operasi kendaraan (BOK) untuk jalan perkotaan di Indonesia, Indonesian Highway Capacity Manual (IHCM) Pd T-15-2005-B Jakarta. 
Bina Marga Dep PU, 1997, Manual Kapasitas Jalan Indonesia, Jakarta.

Hamidi, G.W., Ariany, F., Kwintaryana, W., 2013, Jurnal Analisis Biaya Perjalanan Akibat Tundaan Lalu Lintas (Studi kasus: Ruas Jalan dari Persimpangan Jl. I Gusti Ngurah Rai-Jl. Perum Griya sampai Persimpangan Jl. I Gusti Ngurah Rai-Jl. Siligita), Universitas Udayana Bali.

Lembaga Afiliansi Penelitian dan Industri (LAPI) ITB, 1996, Laporan Akhir Studi Perhitungan Biaya Operasi KendaraanPT. Jasa Marga, ITB Bandung.

Rosid, H., 2006, Tesis Effisiensi Rencana Fly Over Kalibanteng Kota semarang dalam Mengatasi Kemacetan Dari Sisi Pengguna, Universitas Diponegoro Semarang.

Silvia, S., 1999, Perencanaan Geometrik Jalan Raya, Bandung

Supardi, 2013, Aplikasi Statika Dalam Penelitian Konsep Statistika yang lebih Komprehensif, Jakarta

Tamin, O.Z. 2000. Perencanaan dan Pemodelan Transportasi, ITB, Bandung. 